\title{
Entre el derecho de autor y el copyright: Análisis del efecto expansivo de la jurisprudencia del Tribunal de Justicia de la Unión Europea en el copyright británico
}

\author{
Between author's right and copyright: An analysis of the expansive effect \\ of the jurisprudence of the Court of Justice of the European Union \\ on British Copyright Law
}

Felipe Osorio Umaña

University College London, Reino Unido

\begin{abstract}
RESUMEN Este trabajo analiza cómo la armonización europea del derecho de autor ha expandido al copyright británico. El artículo comienza explicando de qué manera se puede entender la expresión expansión. En segundo lugar, se analizará cómo la sentencia Infopaq International A/S con Danske Dagblades Forening ha generado un proceso de expansión de los conceptos fundamentales del copyright británico. Luego de esto, se analizará cómo han cambiado las interpretaciones jurisprudenciales del derecho británico sobre los conceptos de originalidad, objeto de protección e infracción de derechos. Este cambio de interpretación, se concluye, ha tenido un efecto expansivo que afecta las libertades de los usuarios y favorece las pretensiones de propiedad de autores y de quienes ostentan derechos patrimoniales sobre las obras.
\end{abstract}

PALABRAS CLAVE Infopaq, originalidad, infracción, objeto de protección.

ABSTRACT The article analyses how the European armonization of intellectual property has expanded the UK's Copyright. The article will start by explaining in which sense the expression expansion needs to be understood. Secondly, the article will discuss how the ruling in Infopaq International A/S v. Danske Dagblades Forening has prompted an expansion of UK copyright's fundamental concepts. Thirdly, the article will analyse how the judicial interpretations of originality, subject matter, and infringement have changed post-Infopaq. It will be concluded that the change of interpretation has expanded the copyright system, having negative effects on users' freedoms and favouring authors' property claims.

KEYWORDS Infopaq, originality, infringement, subject matter. 


\section{Introducción}

El derecho de autor y el copyright son usualmente presentados como dos sistemas paralelos de protección de las creaciones intelectuales. ${ }^{1}$ Esta distinción, se ha dicho, no solo responde a una diferencia geográfica o de tradición - al ser el primero propio de los países de tradición civilista y el segundo propio del common law-, sino que respondería también a una justificación y lógica diferentes. Mientras que el derecho de autor se justificaría en un derecho natural del autor sobre su obra, el copyright estaría justificado por su naturaleza utilitaria en la búsqueda de la proliferación de nuevas obras; por su parte, mientras que el énfasis del copyright estaría en el reconocimiento del trabajo del autor a través de la protección de derechos económicos, el centro del derecho de autor estaría, en cambio, enfocado en la protección del autor en tanto persona que mantiene una conexión moral o espiritual con la obra creada (Biagioli, 2011), cuestión que se vería reflejada en la importancia de los derechos morales dentro de los sistemas continentales del derecho de autor. ${ }^{2}$

Sin embargo, estas dos tradiciones, que metodológicamente son puestas en paralelo, comparten ciertas raíces históricas y desarrollos comunes. Jane Ginsburg (1990), por ejemplo, nota que es posible encontrar en los orígenes tanto del derecho de autor como del copyright la intención de incentivar la producción de nuevas creaciones inmateriales para lograr objetivos nacionales como la instrucción pública o el progreso del conocimiento. Es decir, ambas tradiciones compartirían, desde sus orígenes, la lógica de otorgar al autor de una nueva obra un derecho o monopolio limitado en el tiempo para incentivar nuevas creaciones.

En este sentido, desde la tradición del derecho de autor continental podemos identificar que la idea del autor como aquella figura solitaria que imprime en la obra su ingenio (Biron y Cooper, 2016: 56) se encuentra directamente relacionada al derecho de propiedad como reconocimiento de dicha capacidad intelectual. Como señala Mario Biagioli, ya en Fichte podemos encontrar la idea de que «si hay algo en un libro que no puede ser, de ninguna manera, alienado de su dueño, ese algo debe calificar como propiedad» (Biagioli, 2011: 1.855; énfasis en el original). ${ }^{3}$ Sin embargo, el reconocimiento del autor mediante el derecho de propiedad tiene, a su vez, un propósito público. Al respecto, por ejemplo, Victor Hugo, en su discurso en el Congreso Literario Internacional de París de 1878, notó la necesidad de diseñar un sistema que

1. En lo que sigue, se utilizará la expresión copyright como sinónimo de la regulación del Reino Unido sobre la materia, lo que deja fuera del término a otras jurisdicciones de la tradición del common law como la australiana o la norteamericana.

2. Al respecto, véanse los capítulos introductorios al copyright y al derecho de autor de Bently y otros (2018), Aplin y Davis (2013) y Walker (2014). En lo que sigue, se utilizará el concepto propiedad intelectual para designar de manera genérica al derecho de autor y al copyright.

3. Las referencias a textos en inglés o sentencias de cortes británicas son traducciones libres del autor. 
pudiera combinar la propiedad del escritor con la necesidad de la existencia del dominio público (Greenleaf y Lindsay, 2018: vii). ${ }^{4}$

Por su parte, la tradición del common law también comparte la preocupación del balance entre el reconocimiento del -o incentivo al- autor y el interés de la sociedad por tener acceso a las nuevas obras. Ya en la que ha sido catalogada como la primera ley sobre propiedad intelectual, el Estatuto de la Reina Ana de 1710, se establecía que el derecho otorgado al autor tenía el propósito de promover la creación de nuevas obras, pues estas permitían el progreso del conocimiento humano. De este modo, el derecho limitado en el tiempo que el Estatuto establecía suponía un acuerdo entre autores, intermediarios y el público en general (Deazley, 2006: 13-14). Una idea similar puede encontrarse en la octava sección del artículo primero de la Constitución norteamericana, la cual, en su cláusula octava, dispone que el Congreso tendrá facultad «para fomentar el progreso de la ciencia y las artes útiles, asegurando a los autores e inventores, por un tiempo limitado, el derecho exclusivo sobre sus respectivos escritos y descubrimientos».

Como podemos ver, aun cuando se ha entendido que ambas tradiciones tienen justificaciones y enfoques distintos, es posible problematizar tal afirmación y encontrar al menos una preocupación común: el balance entre el derecho del autor sobre su obra y el derecho de la sociedad en su conjunto de acceder al conocimiento generado por este.

Sin embargo, pareciera ser que dicho balance no ha podido ser mantenido. Habría entonces unanimidad respecto a que el sistema contemporáneo del derecho de autor y del copyright se han expandido, favoreciendo la privatización nuevos tipos de creaciones intelectuales. Algunos incluso han señalado que la historia de la propiedad intelectual se caracteriza por una «expansión progresiva» de la protección de los autores a través del derecho (Greenleaf y Lindsay, 2018: 10).

La discusión acerca de las causas de la expansión del sistema es amplia. Algunos culpan a la exacerbación de la figura del autor (Rose, 1988; Woodmansee, 1984; Boyle, 1996); otros, a las políticas económicas neoclásicas o neoliberales (Netanel, 1996; Hull, 2019); y otros han intentado dar explicaciones complejas que incluyen factores como la industria del lobby, el uso estratégico del discurso sobre la propiedad, la internacionalización del derecho, entre otros (Bently, 2008). Sin embargo, aun cuando las razones pueden ser múltiples, lo importante es notar que existe una necesidad inherente del derecho de expandirse hacia nuevas áreas no juridificadas. El derecho, en general, necesita regular aquellas prácticas informales a través de la formalidad de lo legal. Esto implica, por tanto, una naturaleza expansiva del derecho (Habermas, 1986:

4. El discurso original puede encontrarse en «Congrès littéraire international de Paris 1878 : présidence de Victor Hugo : comptes rendus in extenso et documents / Société des gens de lettres de France», Bibliothèque Nationale de France, disponible en https://bit.ly/3HPtkmY. 
2.014; Teubner, 1987: 46). En este contexto, no es extraño que el derecho de propiedad intelectual se expanda, puesto que se trata de un área del derecho que se encuentra en una relación directa con los avances tecnológicos (Sherman y Wiseman, 2012): el derecho de autor deberá adaptarse cada vez que una nueva tecnología cambie la manera como se desarrollan las prácticas creativas.

Este trabajo tiene por objeto estudiar parte del proceso expansivo de los regímenes de propiedad intelectual. En específico, analizará cómo la armonización de la propiedad intelectual en el derecho europeo ha influido en el copyright. El caso de estudio es interesante no solo para el análisis de la expansión del derecho de autor europeo y británico, sino también porque se trata de un proceso en el que se ven envueltas las dos principales tradiciones relativas a la protección de las creaciones del intelecto.

El trabajo se estructurará de la siguiente manera: en la primera sección, se delimitará el significado de la palabra expansión para efectos del trabajo, lo cual permitirá determinar en qué sentido esta es relevante para el derecho de autor y por qué supone un riesgo para los intereses generales presentes en ambas tradiciones. La segunda sección presentará el proceso histórico de armonización del derecho europeo, en particular, aquella etapa inaugurada por el Tribunal de Justicia de la Unión Europea (TJUE) con su decisión en el caso Infopaq International A/S con Danske Dagblades Forening (C-5/08, de 2009). Se argumentará que las interpretaciones del TJUE en Infopaq y sus consecuentes desarrollos jurisprudenciales a nivel europeo han tenido un impacto expansivo directo en el copyright. Para mostrar dicho efecto expansivo, la tercera sección analizará cómo los conceptos de originalidad, obra e infracción del copyright han sido reinterpretados luego de Infopaq. Para ello, se analizará tanto la jurisprudencia de las cortes británicas como del TJUE respecto de cada uno de dichos conceptos. Finalmente, se concluirá que el desarrollo jurisprudencial del TJUE ha expandido la protección de quienes ostentan los derechos de propiedad intelectual, lo que ha afectado directamente las posibilidades de interacción entre los usuarios y las obras protegidas.

\section{Delimitación del concepto de expansión en el derecho de autor}

La propiedad intelectual es un área del derecho directamente relacionada con los avances tecnológicos (Goldstein, 2003). Cada vez que una nueva tecnología ha modificado las prácticas creativas, el derecho se ha debido adaptar extendiendo su alcance, por lo general otorgando nuevos derechos a los autores. Así, por ejemplo, derechos de propiedad sobre bases de datos o programas computacionales solo pueden entenderse bajo la necesidad de adaptación de la propiedad intelectual. Esta adaptación, sin embargo, ha tomado usualmente una forma expansiva.

¿Qué entenderemos por expansión del derecho de autor? En el contexto de este trabajo, la expansión del derecho de autor tiene directa relación con la posición nor- 
mativa de los autores respecto de los usuarios -o el público-. Así, cuando señalamos que el derecho de autor se ha "expandido», nos referimos a que la esfera de acción del público con respecto a las obras del intelecto se ha reducido - por consiguiente, la esfera de acción de los titulares del derecho de autor se ha ampliado- ${ }^{5}$ Ahora bien, no todas las modificaciones legales expanden al derecho de autor en el sentido antes descrito. Esto es, no toda modificación formal del derecho de autor tiene efectos expansivos.

Tomemos, por ejemplo, el Tratado de Marrakesh, «Para facilitar el acceso a las obras publicadas a las personas ciegas, con discapacidad visual o con otras dificultades para acceder al texto expreso», el cual otorga una serie de limitaciones y excepciones al derecho de autor para facilitar el acceso a obras por parte de personas ciegas o que presenten alguna discapacidad visual. Analizado formalmente, el Tratado puede entenderse como un caso de expansión del derecho de autor: este expande el alcance del derecho de autor al regular una serie de hipótesis que antes no existían. Además, supone una expansión cuantitativa de los instrumentos internacionales del derecho de autor $y$, una vez ratificado por cada país, supone la obligación de adaptar el derecho nacional para que incluya estas nuevas limitaciones y excepciones. El Tratado, por tanto, es un caso de expansión cuantitativa o formal del derecho de autor.

Sin embargo, esta expansión tiene una particularidad: en vez de otorgar un mayor control sobre las obras, reconoce las necesidades de un grupo específico de usuarios.

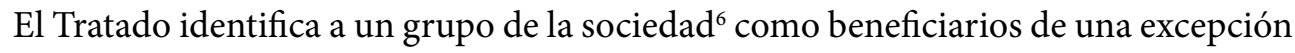
al derecho de autor que los faculta para efectuar los cambios necesarios que permitan la reproducción de obras protegidas (literarias y artísticas) en un formato accesible (artículo 4) y a distribuir de manera transfronteriza dichos ejemplares modificados (artículo 5); todo esto, sin necesidad de obtener la autorización del titular de los derechos. Es decir, el Tratado de Marrakesh supone un paso adelante para la posición de los usuarios en la propiedad intelectual. Por tanto, aun cuando el Tratado supone una ampliación formal del derecho de autor, no supone una «expansión» en el sentido relevante para este trabajo.

Si comparamos la expansión que supone el Tratado con la expansión que supuso, por ejemplo, la Directiva 2006/116/CE del Parlamento Europeo «Relativa al plazo de

5. En lo que sigue, cada uso de la palabra expansión se refiere a la definición señalada.

6. El artículo 3 define como beneficiarios a toda persona «a) ciega; b) que padezca una discapacidad visual o una dificultad para percibir o leer que no puede corregirse para que permita un grado de visión sustancialmente equivalente al de una persona sin ese tipo de discapacidad o dificultad, y para quien es imposible leer material impreso de una forma sustancialmente equivalente a la de una persona sin esa discapacidad o dificultad; o c) que no pueda de otra forma, por una discapacidad física, sostener o manipular un libro o centrar la vista o mover los ojos en la medida en que normalmente se considera apropiado para la lectura; independientemente de otras discapacidades». 
protección del derecho de autor y determinados derechos afines», que extendió el plazo de protección de las obras de cincuenta a setenta años, podemos encontrar que esta expansión es cualitativa o sustantivamente diferente. Al igual que el Tratado, la Directiva amplió formalmente el derecho de autor y supuso un nuevo instrumento legal que debió ser incorporado al derecho nacional de los Estados miembros. Sin embargo, la Directiva no constituye una expansión de las hipótesis en que los usuarios pueden interactuar libremente con las obras protegidas; por el contrario, este nuevo cuerpo legal limita dichas hipótesis al extender el plazo por el cual las obras se mantendrán protegidas por el derecho de autor.

Ambos ejemplos nos permiten distinguir entre expansiones de las esferas de acción de los usuarios - las cuales los autorizan a acceder de manera más fácil a las obras, copiarlas legítimamente, usarlas para nuevas creaciones, etcétera- y las expansiones que limitan la esfera de acción de los usuarios. Visto desde el punto de vista de los propietarios de los derechos, hay expansiones que restringen las posibilidades de los propietarios para excluir a los usuarios de posibles interacciones con sus obras, y otras expansiones que aumentan el poder de excluir a usuarios de dichas interacciones.

Como hemos señalado, este trabajo, al igual que la literatura tradicional sobre la expansión de la propiedad intelectual (Bently, 2008; Netanel, 1996; Liu, 2012), se centrará en el análisis de aquellas expansiones que implican una limitación de las libertades de los usuarios y un aumento en términos de control sobre las obras por parte de propietarios de los derechos de propiedad intelectual. La importancia de tratar este tipo de expansiones radica en que ellas generan un desbalance entre las libertades y necesidades de los usuarios, por una parte, y los derechos de los autores - o de quienes detentan los derechos patrimoniales sobre la obra-, por la otra. Este desbalance afecta no solo las libertades y derechos fundamentales de los usuarios (Netanel, 1996; Boyle, 2008; Lessig, 2004), sino también a la consecución del objetivo declarado por la justificación tradicional del derecho de autor: el incentivo para la proliferación de nuevas obras (Litman, 1999; Boyle, 2003; Cohen, 2006).

Ahora bien, ¿cómo determinar si una nueva regulación ha expandido al derecho de autor en la forma antes descrita? Una posibilidad es comparar formalmente del derecho de autor de dos períodos diferentes; para esto, habría que preguntarse si acaso se han reconocido nuevos derechos, si hay nuevas limitaciones y excepciones al derecho de autor, si hay más o menos mecanismos para exigir el respeto del derecho de autor, etcétera. Cada una de estas preguntas nos permitiría saber si formalmente el derecho de autor se ha expandido. Sin embargo, un criterio tan solo formal como el descrito nos dice poco acerca de cómo funciona el sistema y su extensión sustantiva en términos del alcance real de los derechos, o sobre cómo la jurisprudencia de una determinada legislación ha interpretado los conceptos fundamentales del sistema. Como ha señalado Lionel Bently (2008: 5), este tipo de análisis puede mostrarnos 
«algo sobre cómo las tradiciones legales redactan sus regulaciones, y el rol de los legisladores y jueces en dicha tradición, pero, probablemente, no mucho más que eso».

Es necesario, entonces, un criterio distinto para evaluar la expansión de un sistema de propiedad intelectual. Ya que nuestro foco está puesto en expansiones que aumentan el poder de excluir de los propietarios o que limitan las libertades de los usuarios para interactuar con las obras, el criterio a utilizar debe poder dar cuenta de la operación sustantiva del sistema. Este criterio no puede sino ser cualitativo o sustantivo: no es la extensión formal del derecho lo que nos interesa, sino la extensión sustantiva de la protección que un determinado sistema otorga a los autores y propietarios (Bently, 2008: 5-6). Es decir, la expansión del derecho de autor no puede ser analizada atendiendo a la cantidad de reglas del sistema, sino que a los efectos sustantivos que dichas reglas tienen en la relación entre la protección de las obras y las libertades de los usuarios.

En lo que sigue, se analizará un tipo especial de expansión, la cual podemos llamar interpretativa o jurisprudencial. Este tipo de expansión responde a la naturaleza interpretativa de la actividad jurisdiccional. El derecho, en tanto texto autoritativo, requiere de interpretación. Clientes, abogados, jueces, académicos y estudiantes se ven día a día envueltos en una práctica eminentemente interpretativa. Tanto los estudios críticos del derecho como el realismo americano han mostrado que la determinación de lo que el derecho es no depende de una aplicación mecánica del texto legal, sino que del contexto en el cual la interpretación es llevada a cabo (Leiter, 1999; Unger, 1986: 2). En este sentido, la expansión interpretativa opera dentro de los límites del texto legal sin expandir los confines formales del sistema, sino que los sustantivos.

Puede parecer que la expansión interpretativa solo tendría importancia real en los sistemas del common law en que el precedente juega un rol esencial. Sin embargo, es posible detectar en jurisdicciones civilistas distintas interpretaciones de una misma regla, las cuales expanden o restringen de manera directa al derecho de autor. Así, por ejemplo, es posible encontrar interpretaciones distintas de la regla de tres pasos contenida en el artículo 9(2) del Convenio de Berna para la Protección de las Obras Literarias y Artísticas, y en el artículo 13 del Acuerdo sobre los Aspectos de los Derechos de Propiedad Intelectual relacionados con el Comercio (ADPIC). ${ }^{7}$ Mientras que Francia (Cour de Cassation Français, Mullholand Drive, caso 05-15824, 28 de

7. Convenio de Berna, artículo 9(2): «Se reserva a las legislaciones de los países de la Unión la facultad de permitir la reproducción de dichas obras en determinados casos especiales, con tal de que esa reproducción no atente a la explotación normal de la obra ni cause un perjuicio injustificado a los intereses legítimos del autor». ADPIC, artículo 13, «Limitaciones y excepciones»: «Los miembros circunscribirán las limitaciones o excepciones impuestas a los derechos exclusivos a determinados casos especiales que no atenten contra la explotación normal de la obra ni causen un perjuicio injustificado a los intereses legítimos del titular de los derechos». 
febrero de 2006), Países Bajos (Ministry Press Reviews, Rechtbank Den Haag, caso 192880, 2 de marzo de 2005; Private Copying from Illegal Sources, Rechtbank Den Haag, caso 24669, 25 de junio de 2008) y Bélgica (Google Inc con Copiepresse SCRL, Corte de Primera Instancia de Bruselas, 13 de febrero de 2007) han interpretado de manera restrictiva la regla de tres pasos, limitando la aplicación de excepciones al derecho de autor al cumplimiento de cada uno de los «pasos», Alemania (BGH, Re Suministro de Fotocopias de Artículos de Periódicos por parte de Biblioteca Pública, caso I ZR 118/96, ECC 237), Suiza (Corte Federal Suiza, ProLitteris con Aargaguer Zeitung AG, 39 I.I.C. 990, 2008) y España —en específico, la Audiencia Provincial de Barcelona (AC/2008/1773, 17 de septiembre de 2008) - han interpretado de manera flexible dicha regla, acercándola a la doctrina norteamericana del fair use (Griffiths, 2009; Senftleben, 2010). Esto es, mientras en un grupo de países la interpretación de la regla de tres pasos expandió al derecho de autor, en otros se restringió el poder de exclusión que poseen los titulares de los derechos.

En la siguiente sección, se analizará un caso especial de expansión interpretativa, a saber, el que se ha desarrollado en el copyright producto de actividad armonizadora del TJUE. La importancia de este proceso de expansión radica en que ha obligado al copyright a adaptar sus conceptos fundamentales a ideas que tradicionalmente son asociadas al derecho de autor continental.

\section{Armonización del derecho de autor europeo}

\section{Etapas de armonización: Directivas, recomendaciones y jurisprudencia}

Siguiendo a Bernt Hugenholtz (2013), es posible identificar al menos tres etapas de armonización del derecho europeo sobre propiedad intelectual. El autor distingue cada una atendiendo al órgano o mecanismo por el cual se ha llevado adelante el proceso de armonización.

En una primera etapa, desde 1991 hasta 2001, podemos encontrar un período de armonización por medio de directivas. En este período fueron adoptadas siete directivas de aplicación general a nivel de la Unión Europea, ${ }^{8}$ de las cuales la más relevante

8. Directiva 91/250/CEE del Consejo de 14 de mayo de 1991, sobre la protección jurídica de programas de ordenador; Directiva 92/100/CEE del Consejo de 19 de noviembre de 1992, sobre derechos de alquiler y préstamo y otros derechos afines a los derechos de autor en el ámbito de la propiedad intelectual; Directiva 93/98/CEE del Consejo de 20 de octubre de 1993, relativa a la armonización del plazo de protección del derecho de autor y de determinados derechos afines; Directiva 93/83/CEE del Consejo de 27 de septiembre de 1993, sobre coordinación de determinadas disposiciones relativas a los derechos de autor y derechos afines a los derechos de autor en el ámbito de la radiodifusión vía satélite y de la distribución por cable; Directiva 96/9/CE del Parlamento Europeo y del Consejo de 11 de marzo de 1996, sobre la protección jurídica de las bases de datos; Directiva 2001/84/CE del Parlamento Europeo y del Consejo de 27 de septiembre de 2001, relativa al derecho de participación de beneficio del autor de una obra de arte original. 
es la Directiva 2001/29/CE, «Relativa a la armonización de determinados aspectos de los derechos de autor y derechos afines a los derechos de autor en la sociedad de la información», conocida como Directiva InfoSoc.

La Directiva InfoSoc fue diseñada para lidiar con los desafíos del derecho de autor frente a las nuevas tecnologías y lograr «la creación de un mercado interior y la instauración de un sistema que garantice que la competencia dentro del mercado interior no sea falseada» (considerando primero). Para lograr dichos objetivos, la Directiva armonizó los derechos económicos básicos de reproducción (artículo 2), el derecho de comunicación al público de obras y el derecho de poner a disposición del público prestaciones protegidas (artículo 3) y, por último, el derecho de distribución de las obras (artículo 4), todos de una manera amplia y a prueba de los nuevos avances tecnológicos asociados a internet (Hugenholtz, 2013: 60). Además, introdujo en su tercer capítulo obligaciones a los Estados miembros respecto a la protección de «medidas tecnológicas e información para la gestión de derechos». Sin embargo, la Directiva fue más allá de su objetivo declarado (Greenleaf y Lindsay, 2018: 22; Hugenholtz, 2013: 60) para consagrar, además, una serie de excepciones y limitaciones al derecho de autor (artículo 5).

Tras esta armonización a través de directivas, el derecho de autor europeo entró en una etapa de consolidación, en la que se pasó de una armonización mediante instrumentos legales vinculantes a una, desde 2001 a 2009, mediante soft law (Hugenholtz, 2013: 61). Con excepción de la Directiva 2004/48/CE del 29 de abril de 2004, «Relativa al respeto de los derechos de propiedad intelectual», no hubo durante este período un avance armonizador de las características que encontramos en el anterior. En vez de usar directivas vinculantes, la Comisión Europea centró sus esfuerzos en la publicación de recomendaciones de carácter no vinculantes, como la Recomendación del 18 de mayo de 2005, «Relativa a la gestión colectiva transfronteriza de los derechos de autor y derechos afines en el ámbito de los servicios legales de música en línea»; o de evaluaciones respecto a la adopción de las directivas implementadas en el período anterior, como el Informe de la Comisión al Consejo, al Parlamento Europeo y a Comité Económico y Social «sobre la transposición y los efectos de la Directiva 91/250/CEE sobre la protección jurídica de programas de ordenador»; y propuestas para la futura armonización del derecho europeo, como el Libro Verde del 16 de julio de 2008 (COM 2008, 466 final) sobre «Derechos de autor en la economía del conocimiento».

El año 2009 marca el fin del período de consolidación y el comienzo de una nueva etapa de armonización, ya no liderada por los órganos legislativos de la Unión Europea, sino que por parte del TJUE. ${ }^{9}$ Desde la sentencia del Tribunal en Infopaq

9. Durante el período posterior a 2001, se adoptó la Directiva 2012/28/UE del Parlamento Europeo y del Consejo de 25 de octubre de 2012, sobre ciertos usos autorizados de las obras huérfanas, y la Direc- 
International A/S con Danske Dagblades Forening (C-5/08, 2009), el derecho de autor europeo entró en un proceso de armonización mediante la interpretación judicial de, principalmente, la Directiva InfoSoc. Este proceso interpretativo ha extendido la armonización del derecho de autor europeo a áreas que, en principio, no se encontraban cubiertas por la armonización llevada a cabo por medio de las directivas, en lo que algunos han catalogado como el avance de una agenda activista por medio de la interpretación judicial (Hugenholtz, 2013: 63).

En lo que sigue, se describirán los elementos esenciales de la decisión a la que llegó el TJUE en Infopaq, para luego analizar los efectos que dicha sentencia ha generado en el derecho británico. Esto nos permitirá observar cómo se ha llevado a cabo un proceso de adaptación entre el copyright y el derecho de autor con efectos expansivos.

\section{Armonización por interpretación}

Como hemos señalado, el proceso de armonización del derecho de autor europeo, que comenzó como un esfuerzo legislativo basado en lograr sortear los obstáculos para un comercio sin fronteras dentro de la Unión Europea (Rosati, 2019: 10), ${ }^{10} \mathrm{cam}$ -

tiva 2014/26/UE del Parlamento Europeo y del Consejo de 26 de febrero de 2014, relativa a la gestión colectiva de los derechos de autor y derechos afines y a la concesión de licencias multiterritoriales sobre obras musicales para su utilización en línea en el mercado interior; asimismo, se adoptó el copyright package, esto es, la Directiva (UE) 2019/789 del Parlamento Europeo y del Consejo de 17 de abril de 2019, por la que se establecen normas sobre el ejercicio de los derechos de autor y derechos afines aplicables a determinadas transmisiones en línea de los organismos de radiodifusión y a las retransmisiones de programas de radio y televisión, y por la que se modifica la Directiva 93/83/CEE; la directiva (UE) 2019/79o del Parlamento Europeo y del Consejo de 17 de abril de 2019, sobre los derechos de autor y derechos afines en el mercado único digital y por la que se modifican las Directivas 96/9/CE y 2001/29/ CE; y la Directiva (EU) 2017/1564 del Parlamento Europeo y del Consejo de 13 de septiembre de 2017, junto al Reglamento (UE) 2017/1563 de 13 del Parlamento Europeo y del Consejo de septiembre de 2017, las cuales implementan el Tratado de Marrakesh en la Unión Europea. Asimismo, durante este período encontramos diversas iniciativas de soft law, como el Dictamen de 24 de mayo de 2011 (Com 2011, 287 final) sobre la «Comunicación de la Comisión al Parlamento Europeo, al Consejo, al Comité Económico y social Europeo y al Comité de las Regiones. Un mercado único de los derechos de propiedad intelectual. Estimular la creatividad y la innovación para generar crecimiento económico, empleos de calidad y productos y servicios de excelencia en Europa», o el Libro Verde del 13 de julio de 2011 (Com 2011, 427 final), «Sobre la distribución en línea de obras audiovisuales en la Unión Europea: Oportunidades y problemas en el avance hacia un mercado único digital».

10. Las bases legales de dicho proceso de armonización se encuentran en los artículos 26 y 114 del Tratado de Funcionamiento de la Unión Europea. El artículo 26 del Tratado señala: «Mercado interior, artículo 26: 1) La Unión adoptará las medidas destinadas a establecer el mercado interior o a garantizar su funcionamiento, de conformidad con las disposiciones pertinentes de los tratados. 2) El mercado interior implicará un espacio sin fronteras interiores, en el que la libre circulación de mercancías, personas, servicios y capitales estará garantizada de acuerdo con las disposiciones de los tratados. 3) El 
bió hacia un proceso inorgánico o casuístico, llevado adelante principalmente por el TJUE. Con su decisión en Infopaq, el TJUE llevó a cabo una interpretación de la Directiva InfoSoc que algunos han catalogado de «radical» (Griffiths, 2013: 780), la cual ha tenido amplios alcances en la forma en que la jurisprudencia británica ha debido reinterpretar algunos de los conceptos fundamentales del copyright (Derclaye, 2010: 250).

Antes de Infopaq, el proceso de armonización se había enfocado en aquellos aspectos del derecho europeo que podían poner trabas al objetivo de lograr un fluido funcionamiento del mercado interior (Griffiths, 2013: 780). En ese contexto, la Directiva InfoSoc era el instrumento más importante para el proceso de armonización, ya que, como se ha señalado, armonizaba los derechos de reproducción, de comunicación al público y de distribución, como también las limitaciones y excepciones al derecho de autor. Este proceso de armonización previo a Infopaq, entonces, dejaba los principios fundamentales del copyright intactos y el rol del TJUE limitado a su competencia (Griffiths, 2013: 780). Con Infopaq, sin embargo, la situación cambió drásticamente. Los principios clásicos del copyright comenzaron a ser presionados por la actividad interpretativa del TJUE, lo que ha llevado a una mixtura entre el derecho de autor continental y el copyright, generando una expansión de los conceptos fundamentales de este último.

\section{La controversia en Infopaq}

Infopaq International A/S es una compañía de monitoreo de medios de comunicación y análisis de mercado que publica resúmenes de la prensa danesa y otros periódicos con el objeto de enviarlos a sus clientes. Para proveer sus servicios, la compañía debía cumplir una serie de procedimientos que suponían llevar a cabo copias de los artículos originales. Dicho proceso contemplaba la reproducción de los artículos en diferentes formatos para transformarlos en un documento de once palabras. Finalmente, el producto que contenía el resumen de once palabras de los artículos era comunicado a sus clientes (Infopaq, párrs. 17 a 21).

Danske Dagblades Forening, por su parte, en representación de los periódicos daneses, demandó a Infopaq por la infracción del derecho de autor que dichos periódi-

\footnotetext{
Consejo, a propuesta de la Comisión, definirá las orientaciones y condiciones necesarias para asegurar un progreso equilibrado en el conjunto de los sectores considerados».

Por su parte, el artículo 114 dispone: «Aproximación de legislaciones, artículo 114: 1) Salvo que los tratados dispongan otra cosa, se aplicarán las disposiciones siguientes para la consecución de los objetivos enunciados en el artículo 26. El Parlamento Europeo y el Consejo, con arreglo al procedimiento legislativo ordinario y previa consulta al Comité Económico y Social, adoptarán las medidas relativas a la aproximación de las disposiciones legales, reglamentarias y administrativas de los Estados miembros que tengan por objeto el establecimiento y el funcionamiento del mercado interior».
} 
cos tendrían sobre los artículos de noticias reproducidos dentro del proceso llevado a cabo por Infopaq.

El procedimiento judicial a nivel europeo giró en torno a once preguntas que la Højesteret (Corte Suprema) danesa le refirió al TJUE como petición prejudicial. Estas once preguntas pueden ser resumidas en dos generales: la primera, sobre qué significa reproducción bajo el artículo 2 de la Directiva InfoSoc; y la segunda, sobre el significado del inciso primero del artículo 5 de la Directiva InfoSoc, el cual regula una excepción al derecho de autor en casos de reproducción provisional, transitoria o accesoria.

Con respecto a la primera pregunta, el TJUE estimó de manera preliminar que, al no existir una referencia expresa al derecho interno de los países miembros en el artículo 2 de la Directiva Infosoc, el concepto de reproducción era, por tanto, un concepto autónomo del derecho comunitario. Esto es, la interpretación que el TJUE diera del concepto reproducción sería vinculante y uniforme para toda la Comunidad (párr. 27).

Luego de estimar que el concepto era autónomo del derecho comunitario, el TJUE se refirió a su contenido. Cabe recordar que el artículo 2, letra a) de la Directiva InfoSoc dispone que: «los Estados miembros establecerán el derecho exclusivo a autorizar o prohibir la reproducción directa, provisional o permanente, por cualquier medio y en cualquier forma de la totalidad o parte: a) a los autores, de sus obras». Teniendo en cuenta la redacción del artículo, el TJUE estimó necesario definir, junto con el concepto reproducción, el de obra (párr. 33). Ambas interpretaciones, señaló el TJUE, deben realizarse teniendo en cuenta los objetivos generales de la Directiva InfoSoc y del derecho internacional (párr. 32).

Para llevar a cabo dicha interpretación, el TJUE recurrió al Convenio de Berna, en específico, a su artículo 2, números 5 y 8 , los cuales, al referirse a las obras protegidas, utilizan la expresión «creaciones intelectuales» y excluyen de la protección del derecho de autor a aquellas noticias que tengan el carácter de simples informaciones de prensa, respectivamente. Lo importante de estos dos numerales, señaló el TJUE, es que ambos entienden a las obras protegidas como creaciones intelectuales de sus autores (Infopaq, párr. 34). La idea de que la «obra» objeto de protección debe ser una «creación intelectual» del autor no era ajena al derecho europeo. Es más, en su interpretación del concepto obra, el TJUE hizo referencia a la Directiva 2009/24/ $\mathrm{CE}$, «Sobre la protección jurídica de programas de ordenador» y a la Directiva 96/9, «Sobre la protección jurídica de las bases de datos», ya que ambas directivas definen la obra como una creación intelectual de su autor (párr. 35). ${ }^{11}$ Asimismo, el TJUE hizo

11. El artículo 1 de la Directiva 2009/24/CE dispone que «el programa de ordenador quedará protegido si fuere original en el sentido de que sea una creación intelectual propia de su autor. No se aplicará ningún otro criterio para conceder la protección» (énfasis añadido); por su parte, el artículo 3 de la 
referencia a la Directica 2006/116/CE, «Relativa al plazo de protección del derecho de autor y de determinados derechos afines», la cual en su artículo 6 dispone que las fotografías serán consideradas originales, y por tanto protegidas, siempre y cuando supongan una "creación intelectual propia» del autor. Todas estas referencias permitían al TJUE establecer que la protección del derecho de autor se extendía solo a aquellas obras que fueron una «creación intelectual» de su autor, excluyendo cualquier otro criterio para determinar la originalidad de una obra.

Finalmente, en el párr. 37 de la sentencia, el TJUE entregó el ya famoso criterio para determinar el contenido del requisito de originalidad bajo el derecho comunitario: «En estas condiciones, el derecho de autor a los efectos del artículo 2, letra a), de la Directiva 2001/29 solo se aplica a las obras que constituyen creaciones intelectuales originales atribuidas a este» (énfasis añadido).

Aplicando el estándar de originalidad antes señalado, el TJUE determinó que, aunque las palabras que componen una noticia «no constituyen en sí mismas elementos sobre los que recaiga la citada protección» (párr. 46), sí es posible que determinadas frases o elementos de las frases que constituyen las noticias "puedan transmitir al lector la singularidad de una determinada publicación», permitiendo así comunicar «la expresión de la creación única del autor» (párr. 47). De este modo, para el TJUE, el estándar de originalidad del derecho comunitario permitiría considerar que la reelaboración de un extracto de una obra protegida consistente en, por ejemplo, once palabras, puede ser una reproducción parcial en los términos del artículo 2 de la Directiva InfoSoc y, por tanto, constituir una infracción al derecho de autor (párr. 48).

En relación a la determinación del contenido del artículo 5, inciso primero de la Directiva InfoSoc, relativo a la excepción al derecho de autor en caso de reproducción provisional, transitoria o accesoria, el TJUE señaló que las condiciones para su aplicación eran cumulativas, es decir, para que una reproducción se encuentre bajo la hipótesis de excepción, esta debe ser: i) transitoria o accesoria; ii) formar parte integrante y esencial de un proceso tecnológico; iii) cuya única finalidad sea facilitar una transmisión en una red entre terceras partes por un intermediario, o una utilización lícita; y iv) de «una obra o prestación protegidas, y que no tengan por sí mismos una significación económica independiente».

Además de interpretar los requisitos de la excepción como cumulativos, el TJUE señaló que al tratarse de una excepción que deroga un principio general de la Directiva InfoSoc, como es la protección de las obras que son una creación intelectual de sus autores y la prohibición de su reproducción, esta debía interpretarse de manera

Directiva 96/6 señala que «las bases de datos que por la selección o la disposición de su contenido constituyan una creación intelectual de su autor estarán protegidas, como tal creación, por los derechos de autor. No serán de aplicación otros criterios para determinar si tales bases de datos son susceptibles de dicha protección» (énfasis añadido). 
restrictiva (Infopaq, párr. 56). Que el TJUE haya señalado que la interpretación de las excepciones debía ser restrictiva no es algo nuevo de Infopaq, sino que sigue una línea jurisprudencial del TJUE que puede encontrarse en los casos Kapper (C-476/01, ECR.5205, 2004, párr. 72) y Comisión de las Comunidades Europeas con Reino de España (C-36/05, ECR I-10313, 2006, párr. 31), en que el TJUE ya había mantenido dicha interpretación. Además, argumentó el TJUE, la interpretación restrictiva de la excepción se encontraba alineada con los objetivos generales del proceso de armonización, en tanto otorgaba un nivel alto de protección a los autores, como lo requieren los considerandos cuarto y noveno de la Directiva InfoSoc. ${ }^{12}$ Asimismo, una interpretación restrictiva de la excepción se encuentra en línea con el reconocimiento que la Directiva InfoSoc hace de la regla de tres pasos en su artículo 5 , numeral 5 , el cual señala que las excepciones se aplicarán únicamente en aquellos casos concretos «que no entren en conflicto con la explotación normal de la obra» y que, además, «no perjudiquen injustificadamente los intereses legítimos del titular del derecho» (Infopaq, párr. 58).

Luego de establecer que la excepción en cuestión tenía una aplicación restringida, el TJUE señaló que las condiciones que el artículo 5, numeral 1 imponía debían interpretarse «a la luz de las exigencias de seguridad jurídica que asiste a los autores en la protección de sus obras» (párr. 59). Aplicado al caso Infopaq con Danske Dagblades, esto implicaba, en términos del TJUE, que la conservación y supresión de las reproducciones publicadas por Infopaq no podían depender de un «acto humano discrecional», pues nada garantiza que el usuario «procederá a la supresión efectiva de la reproducción» o que dicha supresión ocurra «cuando ya no se pueda justificar su utilidad en el marco del procedimiento técnico» (párr. 62).

Finalmente, el TJUE se refirió al concepto de reproducción transitoria. Al respecto, señaló que no era posible considerar una reproducción como transitoria si dicha reproducción excede el tiempo necesario para el correcto funcionamiento del proce-

12. El considerando cuarto señala: «La existencia de un marco jurídico armonizado en materia de derechos de autor y de derechos afines a los derechos de autor fomentará, mediante un mayor grado de seguridad jurídica y el establecimiento de un nivel elevado de protección de la propiedad intelectual, un aumento de la inversión en actividades de creación e innovación, incluida la infraestructura de red, lo que a su vez se traducirá en el desarrollo de la industria europea y en el incremento de su competitividad, tanto por lo que respecta al ámbito del suministro de contenido y de la tecnología de la información como, de modo más general, a una amplia gama de sectores de la industria y la cultura. Esta situación preservará el empleo e impulsará la creación de nuevos puestos de trabajo».

Por su parte, el considerando noveno dispone: «Toda armonización de los derechos de autor y derechos afines a los derechos de autor debe basarse en un elevado nivel de protección, dado que tales derechos son primordiales para la creación intelectual. Su protección contribuye a preservar y desarrollar la creatividad en interés de los autores, los intérpretes, los productores, los consumidores, la cultura, la industria y el público en general. Por lo tanto, la propiedad intelectual ha sido reconocida como una parte integrante del derecho de propiedad». 
dimiento técnico al cual asiste. Asimismo, el TJUE señaló que dicho procedimiento debe estar automatizado, incluyendo la supresión de la reproducción una vez que su función ha terminado en el proceso en cuestión (párr. 64).

\section{Entre el derecho de autor y el copyright}

Como hemos señalado, la sentencia del TJUE en Infopaq inaugura una nueva etapa en la armonización del derecho de autor europeo. Esta nueva etapa está caracterizada por el «activismo» del TJUE, el cual ha ido reconfigurando una serie de conceptos fundamentales de la propiedad intelectual mediante interpretaciones que generalmente tienen sus raíces en el derecho de autor continental.

En esta sección se revisará la recepción del derecho comunitario por parte del copyright. Esta recepción no ha estado exenta de problemas pues, como es sabido, ambas tradiciones tienen aproximaciones distintas respecto de los conceptos base de la propiedad intelectual. En lo que sigue, se analizará cómo los conceptos de originalidad, obra e infracción, propios del copyright, han sido influenciados por la actividad jurisdiccional del TJUE. Como se verá, esta recepción ha generado una expansión del copyright que ha impactado directamente en las libertades que los usuarios ostentan para interactuar con las obras protegidas.

\section{Estándar de originalidad}

El estándar de originalidad desarrollado en Infopaq es sustancialmente distinto al estándar de originalidad propio del copyright. Tal como en el derecho de autor continental, para el copyright la originalidad de la obra es un requisito fundamental para la protección de las creaciones intelectuales. Este requerimiento de originalidad se desprende de la sección 1 de la Copyright, Designs, and Patents Act de 1988 (CDPA), la cual dispone que el «copyright es un derecho de propiedad que subsiste en [...] a) obras literarias, dramáticas, musicales o artísticas originales» (énfasis añadido).

En general, la jurisprudencia del Reino Unido ha entendido que una obra es original en tanto tenga su origen en un autor, quien en su elaboración debe haber ejercido su propio esfuerzo, habilidad y juicio. En este sentido, como señaló lord Davey en el caso Walter con Lane (AC 539, 1900), la originalidad de una obra no depende de sus méritos artísticos (p. 552), ${ }^{13}$ sino de que no haya sido copiada en su origen y de la naturaleza del esfuerzo que el autor haya empleado en su creación. ${ }^{14}$

13. En el mismo sentido, University of London Press, Limited con University Tutorial, Limited [1916] 2 Ch 601, Paterson J, 609-610; Ladbroke (Football) Ltd con William Hill (Football) Ltd [1964] 1 W.L.R. 273, Lord Hodson, 285.

14. En algunos casos, sin embargo, los «méritos» o la «naturaleza» artística de la obra sí es relevante al momento de calificarla como una obra sobre la cual el copyright subsiste. Así, por ejemplo, la categoría 
De lo señalado se desprenden los dos elementos esenciales para la determinación del estándar de originalidad bajo el common law británico: primero, la idea del empleo de un esfuerzo (mínimo) en la producción de la obra (Barron, 2002: 379), expresado en la fórmula «esfuerzo, habilidad y juicio»; segundo, la idea de que la obra no debe haber sido copiada en su origen.

Ambos elementos han sido desarrollados por la jurisprudencia británica. Si analizamos el primer elemento, esto es, la necesidad de haber empleado el suficiente esfuerzo, habilidad y juicio, podemos encontrar que ya en 1900 en Walter contra Lane, lord Davey señaló que al «copyright no le interesa la originalidad o el mérito literario del autor o el compositor», sino que, más importante, «es un principio general que un hombre no debe aprovecharse de la habilidad, trabajo y los costos que otro ha empleado, mediante la copia de su producto escrito» (Walter con Lane, p. 552). Ahora bien, esto no quiere decir que cualquier esfuerzo o trabajo es suficiente para dotar a la obra de originalidad. Como señaló lord Oliver en Interlego AG con Tyco Industries ([1989] 1 A.C. 217), «solo un cierto tipo de habilidad, esfuerzo y juicio confiere originalidad» (p. 262). Es decir, aun cuando el requisito de originalidad es bajo, en tanto toda obra requiere en sus orígenes de un mínimo esfuerzo en su creación, este no es inexistente. Por tanto, es necesario emplear el esfuerzo apropiado para el tipo de obra que se trata, así, el esfuerzo requerido para una obra literaria es distinto de aquel requerido para una obra musical o para la creación de una base de datos o de un software. Todas esas expresiones artísticas presentan, en principio, una forma de originalidad diferente, en tanto el esfuerzo literario es distinto al esfuerzo del compositor de una ópera o del programador de un software.

El segundo elemento - la idea de que la obra no debe ser copiada - también tiene una larga historia jurisprudencial. En University of London Press Ltd con Universtity Tutorial Press ([1916] 2 Ch 601), Peterson señaló que «la ley no requiere que la expresión tenga una naturaleza original o novedosa, sino que la obra no debe haber sido copiada desde otra obra - esto es, la obra debe originarse en el autor-» (p. 609). Es decir, la originalidad de una obra no se encuentra en un atributo estético inherente a ella, sino en el hecho de la vinculación causal entre el autor y su creación.

Por tanto, para que una obra sea original bajo el derecho británico anterior a Infopaq, debían estar presentes al menos los dos elementos señalados: primero, que el autor haya empleado el esfuerzo, la habilidad y el juicio necesario para la creación de la obra y, segundo, que esta no haya sido copiada de obra una anterior.

Como se señaló en la sección anterior, Infopaq adoptó una interpretación del re-

de «obras de artesanía artística» (works of artistic craftmanship) requiere para su determinación que la obra tenga un componente artístico, como se determinó en George Hensher Ltd con Restawile Upholstery (Lancs.) Ltd. [1976] AC 64 y se confirmó en la sentencia de la Corte Suprema británica, Lucasfilms and others (Appellants) con Answorth and another (Respondents) [2011] UKSC 39. 
quisito de originalidad similar al de los regímenes jurídicos continentales (la obra como una «creación intelectual del autor»), el cual, al tener el estatus de un concepto autónomo del derecho comunitario, no solo se aplicó a las jurisdicciones de la tradición civil, sino que también al copyright. El criterio establecido en Infopaq, a diferencia del estándar británico, no mira al esfuerzo, habilidad o juicio del autor, sino que pone el énfasis en que la obra, para ser original, debe ser la creación intelectual del autor.

La interpretación del requisito de originalidad entregado en Infopaq continuó desarrollándose en la jurisprudencia del TJUE. En el caso Bezpečnostní softwarová asociase, Svaz softwarové ochrany con Ministerstvo kultury (C-393, 2010), el TJUE debió analizar si la interfaz gráfica de un programa computacional se encontraba protegida por el derecho de autor europeo. Al respecto, el TJUE señaló que aun cuando la interfaz no podría ser protegida a través de la Directiva 91/250/CEE, sobre la Protección Jurídica de Programas de Ordenador - al no ser parte de la operación del software-, esta sí podría ser protegida en el caso de que la interfaz cumpliera con el requisito mínimo impuesto por la Directiva InfoSoc, esto es, que la obra - la interfaz del programa computacional- fuese «una creación intelectual propia de su autor» (párr. 46). Ahora bien, de acuerdo al TJUE, el estándar de originalidad no se encontraría totalmente configurado con la sola demostración de que la obra fue la creación propia de su autor. Además, el TJUE ha entendido que el concepto de originalidad supone que los elementos originales de la obra no pueden estar determinados por las necesidades técnicas que la obra misma le impone al autor. En este sentido, el TJUE fue claro al señalar que, por ejemplo, en el caso de la interfaz gráfica de un programa computacional, la originalidad no puede entenderse satisfecha «por los componentes de la interfaz gráfica de usuario que únicamente se caractericen por su función técnica» (párr. 48).

Siguiendo el criterio de originalidad antes descrito, el TJUE rechazó, en Football Association Premier League Ltd. y otros con QC Leisure y otros (asuntos acumulados C-403/o8 y 429/o8, 2011), la posibilidad de reclamar derechos de autor sobre partidos de fútbol, ya que estos «no pueden calificarse de obras», puesto que para ser calificados como tal deben ser originales «en el sentido de constituir una creación intelectual propia de su autor». Dicha característica no se encontraría en los partidos de fútbol, pues, al estar delimitados por las reglas del juego, estos «no dejan espacio a la libertad creativa, en el sentido de los derechos de autor» (párrs. 96 a 98).

El TJUE también tuvo que referirse a la originalidad de una obra en el caso EvaMaria Painer con Standard VerlagsGmbH (C-145/10, 2011), en el cual se discutieron los derechos de propiedad intelectual sobre retratos fotográficos de autoría de EvaMaria Painer, los cuales fueron utilizados por distintos periódicos alemanes. Al referirse a la posibilidad de que los retratos fotográficos fuesen considerados como obras originales, el TJUE señaló que estos pueden protegerse mediante el derecho de autor 
en tanto expresen las decisiones libres y creativas del autor (párr. 90), como la escenificación, el encuadre, el enfoque o las técnicas de revelado, entre otras (párr. 91). Estas decisiones creativas permiten alcanzar el estándar de originalidad, ya que «mediante estas diversas opciones, el autor de un retrato fotográfico podrá dejar su "impronta personal" en la obra creada» (párr. 92). Siguiendo el mismo criterio, en Football Dataco Ltd y Otros con Yahoo! UK Ltd. (C-604/10, 2012), el TJUE determinó que una base de datos podría considerarse como original si es que expresa la creatividad del autor en su creación (párr. 41).

De la jurisprudencia del TJUE se puede desprender que el requisito de originalidad supone que la obra protegida debe ser un objeto expresivo determinado que refleja la influencia del autor, quien, a su vez, la ha producido dentro del marco de decisiones libres y creativas no constreñidas por las limitaciones o necesidades técnicas propias de la obra. Aun cuando el desarrollo jurisprudencial del TJUE parece limitar el alcance de la protección del derecho de autor al determinar el contenido de la «originalidad», en los hechos, dicho concepto ha sido interpretado por el TJUE de manera expansiva, puesto que es capaz de contener prácticamente cualquier tipo de expresión que refleje las decisiones autorales de su creador (Pila y Torremans, 2016: 252).15

¿Cómo ha influido en el copyright el estándar de originalidad desarrollado por el TJUE? En un primer momento, el lenguaje propio del estándar de originalidad continental no fue recibido por las cortes británicas. En Newspaper Licensing Agency con Meltwater Holding ([2010] EWHC 3099 (Ch)), el primer caso británico luego de Infopaq, el Tribunal Superior de Inglaterra y Gales (High Court of England and Wales) confirmó que el estándar de originalidad requería del empleo de habilidad y esfuerzo en la creación de la obra, sin aplicar el lenguaje de la «creación intelectual propia del autor» desarrollado por Infopaq (párr. 30).

Sin embargo, la jurisprudencia más reciente parece haber abierto las puertas a la influencia europea. En Temple Island Collections Ltd con New English Teas ([2012] EWPCC 1), el Patents County Court para Inglaterra y Gales se pronunció sobre la originalidad de una fotografía en blanco y negro en la cual se retrataba un bus de dos pisos rojo (double-decker bus) cruzar el puente de Westminster. Para analizar el caso, el juez Birss se centró en determinar si la fotografía podía entenderse como la

15. Algunos de los pocos casos en que el TJUE ha excluido a una obra del alcance de la protección del derecho de autor son: la mera expresión de una idea o colección de ideas, en línea con el artículo 9(2) del ADPIC, que dispone: «La protección del derecho de autor abarcará las expresiones pero no las ideas, procedimientos, métodos de operación o conceptos matemáticos en sí»; los eventos deportivos (Football Association Premier League Ltd. y Otros con QC Leisure y Otros (Asuntos acumulados C-403/o8 y 429/o8, 2011)); palabras individuales (Infopaq); y sabores (Levola Hengelo BV con Smilde Foods BV, Caso C-310/17, 2018). 
«creación intelectual» del su autor, haciendo eco al lenguaje de la jurisprudencia del TJUE. En ese contexto, el juez Birss sostuvo que una fotografía podía ser considerada original en referencia a tres criterios: primero, con respecto al ángulo de la foto, la luces y sombras, la exposición y aquellos efectos añadidos mediante filtros; segundo, mediante la creación de la escena fotografiada; y, tercero, la originalidad podía derivar de encontrarse en el lugar y momento correcto (párr. 22). Tomando dichos criterios en consideración, el juez Birss concluyó que la foto en cuestión, aun cuando contenía elementos icónicos (no originales) de Londres, mostraba la originalidad necesaria para obtener protección. Así, el juez Birss entregó una interpretación del requisito de originalidad similar al estándar europeo: una fotografía sería original si es una "creación intelectual propia del autor, tanto en términos de las elecciones creativas relativas a la fotografía misma [...], como también en términos del esfuerzo subsecuente a la realización de la fotografía relativo a la manipulación de la imagen para lograr el sentido estético visual propio de esta» (párr. 51). En este sentido, el juez Birss adaptó el lenguaje del copyright (basado, anteriormente, en el «esfuerzo, habilidad y juicio» del autor) al lenguaje propio del derecho de autor europeo. Como señala Eleonora Rosati (2019: 181), Temple Island Collections inaugura la recepción del estándar de originalidad europeo en el Reino Unido.

Es habitual señalar que el estándar de originalidad del derecho de autor es superior al estándar de originalidad requerido por el copyright (Walker, 2014; Rosati, 2019: 181). Sin embargo, ¿ es posible afirmar tajantemente que el estándar continental propio del derecho de autor es más exigente que el estándar del copyright? El objeto de este trabajo no es hacer un análisis pormenorizado de las diferencias de ambos criterios, pero parece ser que dicha afirmación debe ser matizada. Dos casos del copyright británico pueden ilustrarnos: si es que el estándar de originalidad del derecho de autor es más exigente que el estándar tradicional británico, entonces, menos obras debiesen quedar protegidas luego de Infopaq.

El primer caso es Walter con Lane, en el cual la House of Lords tuvo que resolver sobre los derechos de propiedad que Walter y The Times reclamaban sobre las transcripciones literales de los discursos que el conde de Rosebery pronunció en público entre 1896 y 1898. El periódico The Times empleó a una serie de reporteros para transcribir, a mano y en vivo, los discursos del conde de Rosebery. Las transcripciones eran, en principio, de propiedad del periódico, pues los periodistas habían sido empleados por este para dichos efectos. En 1899, John Lane publicó un libro con los discursos de lord Rosebery -incluyendo aquellos transcritos por The Times-, los cuales eran precedidos de notas explicativas breves. Ante esto, el periódico demandó a John Lane por la infracción de sus derechos sobre los discursos transcritos, argumentando que eran ellos (el periódico) los autores de dichas transcripciones.

Para determinar si las transcripciones de los discursos eran una obra protegida por el copyright, la House of Lords tuvo que analizar su originalidad. Al respecto, 
como señalamos, sostuvo que para el derecho no es relevante la calidad estética o artística de la creación, sino que el esfuerzo, habilidad y juicio empleado en la creación, el cual, sin duda, se encontraba presente en la labor de los periodistas que habían llevado a cabo las transcripciones. Por tanto, la House of Lords concluyó que los reporteros sí podían ser considerados como los autores de la obra y, por tanto, al reproducirse los discursos transcritos en una obra distinta era posible considerar dicha reproducción como una infracción a la propiedad intelectual del periódico.

Ahora bien, ¿cómo se habría resuelto el caso bajo el estándar de originalidad posterior a Infopaq? Pareciera ser que la resolución del caso bajo el nuevo estándar de originalidad acarrearía una solución diametralmente distinta. El criterio post-Infopaq estima - como el TJUE señaló en Football Dataco Ltd. y Otros con Yahoo! UK Ltd. - «irrelevante» el estándar del «esfuerzo, habilidad y juicio». En cambio, el centro del análisis se encuentra en una característica propia de la obra, a saber, que esta sea la «expresión de la creación intelectual del autor». ${ }^{16}$ Así, la mera transcripción de un discurso difícilmente puede mostrar una expresión propia del autor, de modo que, bajo el estándar de originalidad post-Infopaq, la sola transcripción de los discursos no podría entenderse como una «obra» original susceptible de ser protegida. En este sentido, el estándar post-Infopaq parece haber elevado el requisito de originalidad del copyright: ya no sería el mero empleo de esfuerzo el que justifica la protección, sino que dicha protección derivaría de la acción creativa del autor, criterio que sería sustancialmente superior.

Sin embargo, es posible encontrar casos en que el estándar de originalidad no solo parece que no ha sido elevado, sino que, por el contrario, parece haber sido disminuido. En 1939, el Comité Judicial del Consejo Privado del Reino Unido (Judicial Committee of the Privy Council) decidió el caso Francis Day and Hunter, Limited con Twentieth Century Fox Corporation, Limited ([1940] A.C. 112), en el cual se discutió la infracción al derecho de propiedad intelectual sobre el título de la canción The man who broke the bank at Monte Carlo, publicada en el Reino Unido en 1862, el cual fue utilizado por la película homónima exhibida en Canadá en 1935. La disputa se centró en la posibilidad de reclamar derechos de propiedad intelectual sobre una obra literaria, en este caso, el título de la canción, compuesta por nueve palabras. La demanda no prosperó, ya que, en palabras de lord Wright:

Es un principio general que un título no puede, por sí mismo, ser objeto de protección [subject matter] del copyright. Esto, pues, como regla general, un título no supone una composición literaria y no es lo suficientemente sustancial para justificar el reclamo por protección (p. 123).

16. Véase la sentencia del Tribunal de Justicia de la Unión Europea, SAS Institute con World Programming Ltd., asunto C-406/10, 2012, párr. 69. 
Este criterio, sin embargo, parece haber cambiado post-Infopaq. Como ya se ha señalado, en Infopaq el TJUE determinó que es posible calificar a una obra compuesta por once palabras como original, siempre y cuando cumpla con el requisito de ser la expresión de una creación propia del autor. Como señaló el TJUE en Infopaq, las palabras consideradas de forma aislada no constituyen una creación intelectual de quien las emplea, salvo que su combinación genere frases sueltas -o elementos de frases- que «puedan transmitir al lector la singularidad de una determinada publicación [...] haciéndolo partícipe de un elemento que condensa la expresión de la creación intelectual única del autor» (párr. 47). Es decir, el principio establecido en Francis Day respecto de la no protección de títulos por carecer de un aporte sustancial por parte del autor pareciera haber sido superado por el estándar de originalidad del TJUE, el cual permite la protección de frases o títulos en cuanto cumplan con el requisito de originalidad ya descrito.

De lo expuesto, podemos observar cómo el desarrollo jurisprudencial armonizador del TJUE ha influido en el estándar de originalidad clásico del copyright, el cual pasó de ser un estándar enfocado en la «habilidad, esfuerzo y juicio» del autor como criterio principal, a ser un estándar centrado en la determinación de la obra como expresión de una creación intelectual propia del autor. Sin embargo, tal como los casos revisados lo demuestran, no es posible determinar de manera categórica que la interpretación del TJUE ha tenido un efecto expansivo general en el copyright. Aun cuando hay casos en que el criterio de Infopaq expande el alcance del derecho británico, es posible encontrar casos en que el mismo criterio limita dicha expansión. Sin embargo, sí es posible argumentar, en línea con James Griffiths (2013), que la introducción de un criterio desmaterializado de originalidad, en el cual lo importante es la creatividad y no el objeto en el cual ella se encuentra exteriorizada, puede propender a la expansión del copyright, el cual, tradicionalmente, contuvo dicha expansión gracias a los límites físicos de la obra. En este sentido, siguiendo a Pila y Torremans (2016: 253), es posible afirmar que la interpretación del TJUE en Infopaq contiene una definición expansiva de la originalidad, pues permite abarcar prácticamente «cualquier selección o arreglo de palabras, sonidos u otros elementos expresivos» mientras respondan a las elecciones creativas del autor.

\section{Expansión del objeto de protección}

Una gran diferencia entre el derecho de autor y el copyright es la forma en que ambos regulan el objeto susceptible de ser protegido mediante la propiedad intelectual. Mientras el derecho de autor generalmente regula el objeto de protección mediante una lista no taxativa de obras, de manera similar al artículo 2 del Convenio de 
Berna, ${ }^{17}$ el copyright regula el objeto de protección (subject matter) mediante una lista exhaustiva de obras.

Así, la CDPA regula en sus secciones 3 a 8 aquellas obras que pueden ser objeto de protección: las obras literarias, dramáticas, musicales, artísticas y cinematográficas, las grabaciones sonoras, las transmisiones (broadcasts) y las ediciones publicadas o arreglos tipográficos. De este modo, bajo la CDPA, para que una obra original pueda ser protegida, requiere ser susceptible de calificación bajo alguna de estas categorías. ${ }^{18}$

La situación del derecho británico post-Infopaq parece haber cambiado sustancialmente, en lo que podemos calificar como una expansión del objeto de protección. Es decir, luego de la sentencia del TJUE en Infopaq, obras que antes no estaban protegidas mediante copyright ahora sí lo estarían, gracias a la interpretación del objeto de protección dada por el TJUE. Esto, ya que, si la interpretación entregada por el TJUE en Infopaq se aplicara directamente al copyright, colapsaría el concepto de objeto susceptible de protección o subject matter.

Como se señaló en la sección anterior, el TJUE en Infopaq estimó que para que una obra fuese protegida por el derecho de autor, esta debía ser la creación intelectual propia de su autor. Esto, llevado al terreno del objeto de protección, implica que el requisito determinante para la protección es, precisamente, la originalidad de la obra y no su pertenencia a una determinada categoría. Este razonamiento fue confirmado y desarrollado en Bezpečnostní Softwarová Asociace, en que el TJUE, pese a reconocer que la interfaz gráfica de un programa computacional no podía ser protegida por la Directiva 91/250/CEE, sobre la Protección Jurídica de Programas de Ordenador, sí podía ser protegida bajo la Directiva InfoSoc, con la originalidad como el único requerimiento para dicha protección (párr. 46).

17. El artículo 2, numeral 1 del Convenio de Berna dispone: «Los términos obras literarias y artísticas comprenden todas las producciones en el campo literario, científico y artístico, cualquiera que sea el modo o forma de expresión, como los libros, folletos y otros escritos; las conferencias, alocuciones, sermones y otras obras de la misma naturaleza; las obras dramáticas o dramático-musicales; las obras coreográficas y las pantomimas; las composiciones musicales con o sin letra; las obras cinematográficas, a las cuales se asimilan las obras expresadas por procedimiento análogo a la cinematografía; las obras de dibujo, pintura, arquitectura, escultura, grabado, litografía; las obras fotográficas a las cuales se asimilan las expresadas por procedimiento análogo a la fotografía; las obras de artes aplicadas; las ilustraciones, mapas, planos, croquis y obras plásticas relativos a la geografía, a la topografía, a la arquitectura o a las ciencias». En el mismo sentido, véase el artículo 3 de la Ley 17.336 sobre Propiedad Intelectual chilena, la cual contempla una lista no taxativa de obras protegidas.

18. Además de la originalidad y pertenencia a la categoría respectiva, la CDPA requiere que la obra se encuentre fijada materialmente (sección 3); en el caso de las obras no autorales (obras cinematográficas, grabaciones sonoras, transmisiones o ediciones publicadas), estas no deben ser copiadas (secciones 9 y 12), es decir, no hay un requerimiento de originalidad; la obra debe ser suficientemente calificada, esto es, que la obra tenga una conexión con el Reino Unido, ya sea por medio de su autor, el país de publicación o el lugar de transmisión (secciones 154 a 156); y, por último, la obra no debe ser de aquellas excluidas expresamente por razones de política pública. Al respecto, véase Bently y otros (2018: 90-124). 
Esta interpretación puede verse claramente en el caso Football Association Premier League con QC Leisure, en que el TJUE rechazó la posibilidad de que partidos de futbol fuesen protegidos por el derecho de autor, ya que no podían ser calificados como obras. Esto es, el evento deportivo no podía, en ningún caso, entenderse como la creación propia de un autor (párrs. 96-97). El mismo razonamiento fue adoptado en el caso Levola Hengelo BV con Smilde Foods BV (C-310/17, 2018), en que el TJUE debió pronunciarse sobre si era posible proteger el sabor de un queso para untar ( $\mathrm{He}$ ksenkaas) a través de la propiedad intelectual. El razonamiento del TJUE comenzó señalando que para que un objeto sea susceptible de protección, requería que «sea original, en el sentido de constituir una creación intelectual propia de su autor» (párr. 36), es decir, «la calificación como obra [...] se reserva a los elementos que expresan dicha creación intelectual» (párr. 37). Sin embargo, el TJUE limitó el concepto de obra señalando que no basta con la mera originalidad, sino que el objeto mismo debe, a su vez, ser susceptible de determinación objetiva:

Por lo tanto, el concepto de obra contemplado en la Directiva 2001/29 implica necesariamente una expresión del objeto de protección del derecho de autor que la identifique con suficiente precisión y objetividad, aun cuando esta expresión no sea necesariamente permanente (párr. 40).

Fue precisamente esa falta de precisión y objetividad la que privó a Levola Hengelo de la protección del sabor de su producto.

El razonamiento del TJUE al referirse sobre lo que califica como una obra bajo la Directiva InfoSoc da a entender que lo crucial no es la posibilidad de clasificarla dentro de una categoría en específico, sino que el estatus de «obra» le da la originalidad. En palabras de Jonathan Griffith (2013: 782):

La condición creativa no solo opera simplemente como un prerrequisito para la existencia de una obra objeto que sea objeto de la protección del copyright [...], sino como sinónimo de obra y, por tanto, como el único elemento relevante para el merecimiento de protección.

El proceso de armonización propiciado por la actividad jurisprudencial del TJUE ha solidificado la idea de una lista no exhaustiva de obras que pueden ser objeto de protección. Esta interpretación tiene un impacto directo en el copyright, ya que el TJUE ha considerado que la definición y conceptualización de lo que constituye una obra susceptible de protección mediante propiedad intelectual corresponde a una interpretación de un concepto autónomo del derecho comunitario (Handig, 2010:56) y, por tanto, aplicable directamente en el derecho británico.

Es posible encontrar la influencia del criterio europeo sobre el copyright en el caso SAS Institute con World Programming ([2013] EWHC 69 (Ch)), en el cual el Tribunal Superior de Inglaterra y Gales sostuvo que, aun cuando una creación no pudiera ser 
subsumida en una de las categorías de la CDPA, esta podría igualmente ser protegida mediante propiedad intelectual, puesto que el listado de obras literarias que la CDPA contiene no tendría una naturaleza taxativa. Esta interpretación supone una apreciación totalmente distinta a la interpretación tradicional de las cortes británicas pre-Infopaq (Bently y otros, 2018: 58-59). En palabras del juez Arnold:

Que la no pertenencia de una obra en particular a una de las categorías de obras listadas en la Sección 1(1)(a) de la Copyright, Designs and Patents Act de 1988 es una objeción fatal a la posibilidad de reclamar derechos sobre ella es discutible [...]. Sin embargo, sobre lo que no hay duda es que la potencial obra protegida debe ser una obra literaria o artística bajo la definición del artículo 2, numeral primero del Convenio de Berna (SAS Institute con World Programming, párr. 27).

La interpretación del TJUE en Infopaq tiene un impacto expansivo en el copyright británico. Más obras han entrado al dominio de la protección de la propiedad intelectual, pues, de seguirse la interpretación del TJUE en Infopaq, ya no sería necesario que una determinada obra, además de ser original, deba ser susceptible de clasificación bajo una de las categorías de la CDPA.

Dos casos pueden ayudar para ilustrar la potencial expansión del derecho británico. El primero es Creation Records Ltd. con News Group Ltd ([1997] EMLR 444). En este caso se disputó la protección de la portada del disco Be here now, del grupo británico Oasis. El 16 de abril de 1997, Oasis se reunió en el Stocks Country Club Hotel para fotografiar la que sería la portada de su nuevo disco. Bajo la dirección artística de Noel Gallagher, se dispusieron una serie de objetos alrededor de una piscina, dentro de los cuales se encontraba un Rolls Royce emergiendo del agua. En paralelo, el periódico The Sun había reservado dos habitaciones en el mismo hotel con el objeto de paparazzear la sesión de fotos del grupo musical, logrando obtener fotografías similares a las que finalmente fueron utilizadas por el grupo. Estas fotografías fueron publicadas por el diario el 18 de abril de dicho año. Creation Records, representantes de Oasis, demandaron al periódico reclamando una infracción al copyright que ellos tendrían sobre la composición física de los objetos y sobre las fotografías de dicha composición. En subsidio, reclamaron una infracción de deberes de confidencialidad (breach of confidence) al publicar las fotos sin el consentimiento de la banda.

$\mathrm{Al}$ respecto, el juez Lloyd analizó la composición para intentar determinar si es que era posible subsumirla bajo alguna de las categorías contempladas en la CDPA. Primero, el juez desestimó la posibilidad de que la composición fuese una «obra dramática», ya que era de naturaleza estática, sin poseer «movimiento, historia o acción» (párr. 7). Luego, estimó la posibilidad de que la composición fuese una «obra artística» en la forma de una «escultura», de una «obra de artesanía artística» o de un collage. El juez señaló que no era posible asemejar la composición a una escultura o a una obra de artesanía artística, ya que ningún elemento de ella había sido «tallado, 
modelado o fabricado» de alguna manera similar a como una estatua es fabricada (párr. 8). La posibilidad de que la composición fuese un collage fue desestimada porque el entendimiento tradicional de este tipo de obras requiere «el uso de pegamento u otro adhesivo similar en el proceso de producción de la obra visual» (párr. 10), cuestión que no estaba presente en la composición diseñada por Noel Gallagher. Por estas razones, el juez Lloyd rechazó que la composición estuviese protegida por el copyright. Sin embargo, se afirmó que el actuar del periódico infringía los deberes de confidencialidad envueltos en el contexto en que las fotografías fueron tomadas, pues el éxito comercial de la actividad llevada a cabo por parte de Oasis dependía de que el grupo pudiera mantener la exclusividad sobre las fotografías.

En caso de haber seguido el criterio desarrollado por el TJUE, el juez Lloyd se habría visto obligado a otorgar protección a Creation Records y a Oasis - mediante el reconocimiento de copyright, no a través de la infracción a los deberes de confidencialidad-, ya que, como hemos señalado, lo relevante no sería la clasificación de la obra dentro de la lista taxativa, sino que el cumplimiento del requisito de originalidad, el cual se transforma en el elemento clave para determinar si nos encontramos frente a una obra o no. En este sentido, el criterio de Infopaq para determinar si una obra es susceptible de protección difumina la relevancia del listado obras susceptibles de ser protegidas por el copyright, lo que abre la puerta a la protección de obras que antes no estaban contempladas por el ordenamiento jurídico británico.

En el segundo caso, Lucasfilms con Ainsworth ([2011] UKSC 39), la Corte Suprema británica conoció de la disputa entre los productores de Star wars y Andrew Ainsworth, quien produjo durante el proceso de creación de la primera película de la saga (1977) los prototipos para la fabricación de los cascos utilizados por los personajes stormtroopers. Una vez que George Lucas aprobó dichos prototipos, Ainsworth procedió a fabricar 50 cascos, los cuales tenían el objetivo de servir como insumos para las grabaciones (props). En 2004, Ainsworth comenzó a utilizar los moldes originales de los cascos para fabricar y distribuir nuevas versiones, lo que en opinión de Lucasfilms infringía los derechos de propiedad intelectual que tenía sobre las creaciones que se realizaron durante el proceso de producción y rodaje de las películas. Puesto que el copyright británico contempla una lista taxativa de obras protegibles, la disputa giró en torno a la naturaleza legal de los cascos, en particular, acerca de si ellos podían ser considerados como «esculturas» bajo la sección 4(1)(a) de la CDPA 1988. ${ }^{19} \mathrm{Al}$ analizar la cuestión, la Corte Suprema señaló que los cascos no podían ser calificados como «esculturas» y, por ende, quedarían fuera de la protección de la

19. La determinación de la naturaleza de los cascos no solo tenía relevancia para la protección bajo copyright, sino que también para la aplicación de las excepciones al copyright de las secciones 51 y 52 de la CDPA 1988 (esta última derogada en 2016), las cuales permitían la producción de artículos provenientes de diseños que no fueran «obras artísticas», dentro de las cuales se encuentran las esculturas. 
propiedad intelectual, ya que ellas habían sido creadas con un fin utilitario (servir para la producción y filmación de las películas), no con el fin de ser una escultura propiamente tal, como exigía la sección 4(2) de la CDPA.

La interpretación de la Corte Suprema británica habría sido distinta en caso de seguir la jurisprudencia del TJUE. Esto, pues, como se ha señalado, el TJUE ha entendido que los listados de obras objeto de protección tienen el carácter de no exhaustivas, por lo que lo relevante para la protección de una obra es el que esta sea original y objetivamente determinable, características que los cascos de los stormtroopers imperiales sí poseían. Es decir, mientras que la aplicación del criterio tradicional del derecho británico (exhaustividad de la lista de obras protegidas) permitió a la Corte Suprema excluir los cascos de la protección del derecho, el criterio del TJUE habría entendido que los cascos eran, efectivamente, una obra susceptible de protección.

Ambos ejemplos permiten notar cómo el proceso de armonización llevado adelante por el TJUE expande, en principio, la protección que originalmente proveía el derecho británico. Infopaq abrió la puerta a la idea de que una lista exhaustiva propia del copyright sería incompatible con la interpretación del TJUE (Bently y otros, 2018: 58-62; Griffiths, 2013: 785). Por tanto, de adoptarse el criterio otorgado en Infopaq, el objeto de protección del copyright sería sustancialmente expandido, abarcando no solo aquellas obras que pueden subsumirse bajo alguna de las categorías tradicionales, sino también a todas aquellas que cumplan con el criterio de originalidad establecido por la jurisprudencia del TJUE.

\section{Interpretación expansiva de la infracción de derechos de propiedad intelectual}

El proceso de armonización llevado adelante por el TJUE también ha tenido una influencia directa sobre cómo se analizan las infracciones al copyright. Esta influencia se ha manifestado, principalmente, en un cambio en la interpretación del concepto de infracción, el cual ha sufrido una expansión considerable post-Infopaq.

Para entender la expansión del concepto de infracción en el derecho británico, antes es necesario establecer cuál era el criterio tradicional que dicha tradición utilizaba. Desde la Copyright Act de 1911, el derecho británico ha protegido al autor no solo contra la copia literal de su obra, sino también contra cualquier acto que pueda tomar una parte sustancial de esta. Esta referencia a actos que infringen una parte sustancial de la obra se encuentra reconocida en la sección 16 de la actual CDPA. $\mathrm{Al}$ respecto, la ley británica señala que el copyright sobre una obra es infringido por aquella persona que «sin la autorización del autor realiza, o autoriza a otros a realizar, cualquiera de los actos prohibidos por el copyright» (subsección 2), entendiendo que dichos actos prohibidos se refieren «a la obra completa o a cualquier parte sustancial de ella» (énfasis añadido), los que pueden ser directos o indirectos (subsección 3 ). ${ }^{20}$

20. Sección 16(2)(3) CDPA: «2) El copyright que subsiste sobre una obra es infringido por la persona 
El reconocimiento de la posibilidad de infringir una obra protegida mediante la copia de una parte sustancial de esta permite que el sistema británico proteja la obra tanto contra copias literales de la obra en su totalidad, como también aquellos casos en que lo copiado es solo una parte del objeto protegido, siempre y cuando dicha parte sea un componente sustancial de la obra en su totalidad. Así, por ejemplo, existiría la posibilidad de infracción incluso en casos en que lo tomado de la obra original luego sea transformado a un soporte o material diferente (King Features Syndicate Inc con O. and M. Kleeman ([1941] A.C. 417).

Bajo el estándar tradicional del copyright se ha entendido que el juez, para evaluar si lo tomado de la obra original es una parte sustancial de esta, no debe enfocarse en la cantidad de elementos copiados desde la obra, sino que en la cualidad o calidad de dichos elementos. Esta interpretación fue sostenida por lord Millet en el caso Designers Guild con Russel Williams ([2000] 1 WLR 2416), quien señaló:

Una vez que el juez ha determinado que los diseños de los demandados incorporan características que han sido tomadas desde la obra [copyright work], la pregunta es si acaso lo tomado constituye el todo o una parte sustancial de la obra protegida. Esta determinación es una cuestión de impresión, pues la determinación sobre si la parte tomada es sustancial debe realizarse atendiendo a sus cualidades más que a la cantidad tomada (p. 2.426; énfasis añadido).

Asimismo, Lord Millet aclaró que la parte tomada debía ser sustancial para la obra original, no para la obra del demandado. Por tanto, si lo tomado desde la obra original es sustancial para esta, entonces es irrelevante si es que dicha parte es utilizada de manera accesoria en la obra del hipotético infractor. Es decir, es posible que se esté frente a una infracción del copyright aun cuando la obra del demandado sea radicalmente diferente respecto de la obra original (Designers Guild, p. 2.425).

En general, entonces, lo relevante para la determinación de una posible infracción al copyright es la constatación de que el demandado ha incluido en su obra una parte sustancial de las habilidades, esfuerzo y juicio empleados por el autor original (Rosati, 2019: 185). Como se ha señalado, la naturaleza sustancial del elemento no depende de la cantidad de elementos tomados desde la obra original, sino que de las cualidades de dichos elementos.

\footnotetext{
que, sin la autorización del titular del derecho realiza, o autoriza a otras a realizar, cualquiera de los actos prohibidos por el copyright. 3) Las referencias que se hacen en esta parte a la realización de un acto prohibido por el copyright sobre una obra corresponden: a) a la obra en su totalidad o a cualquier parte sustancial de esta, y b) sea esta acción directa o indirecta». El original: "(2) Copyright in a work is infringed by a person who without the licence of the copyright owner does, or authorises another to do, any of the acts restricted by the copyright. (3) References in this Part to the doing of an act restricted by the copyright in a work are to the doing of it: (a) in relation to the work as a whole or any substantial part of it, and (b) either directly or indirectly».
} 
Jonathan Griffiths ha señalado que la interpretación tradicional del derecho británico se encuentra altamente influenciada por un entendimiento particular del objeto de protección del copyright. Para Griffiths, la sola idea de que pueda haber una infracción a la propiedad intelectual mediante la utilización de una parte sustancial de la obra original supone la inmaterialidad del objeto de protección.

Esta idea afecta de manera directa al tipo de análisis que una corte debe llevar a cabo en un caso de infracción de la propiedad intelectual. Primero, la corte debe identificar la obra del demandante, esto es, la forma física en que el esfuerzo mental del autor ha sido materializado (Griffiths, 2013: 771); en segundo lugar, la corte debe determinar si es que el demandado ha utilizado dicho esfuerzo, materializado en la obra, en su totalidad o solo una parte, la cual puede ser sustancial o insustancial. En este sentido, para la interpretación tradicional del derecho británico, la forma (el dibujo, el libro, la pieza musical, etcétera) es solo el «recipiente en el cual reside el verdadero objeto del derecho» (Griffiths, 2013: 771). Esto explicaría por qué el objeto de protección es inmaterial: lo protegido no es el objeto físico en el que se expresa lo creado, sino el trabajo inmaterial - el esfuerzo, habilidad o juicio del autor- que se materializa en la obra. ${ }^{21}$

En contraposición, la regulación europea respecto a las infracciones al derecho de autor no hace referencia a la posibilidad de infracción al tomar una parte sustancial de la obra original. Las directivas sobre protección de programas computaciones, sobre bases de datos y la Directiva InfoSoc, en cambio, disponen que los autores tienen el derecho a controlar la reproducción de la totalidad de su obra o de parte de ella.

En Infopaq, el TJUE debió analizar el contenido del artículo 2 de la Directiva InfoSoc, el cual dispone que «los Estados miembros establecerán el derecho exclusivo a autorizar o prohibir la reproducción directa o indirecta, provisional o permanente, por cualquier medio y en cualquier forma, de la totalidad o parte: a) a los autores, de sus obras» (énfasis añadido). En su interpretación, el TJUE señaló que las partes de una obra no debían ser tratadas de forma diferente respecto de la obra en su totalidad, es decir, cada parte de la obra se encontraría protegida en tanto estas comparten la originalidad de la obra en su conjunto (Infopaq, párr. 38). Puede entenderse, entonces, que para el criterio establecido en Infopaq bastaría con que el demandado tomara o copiara una parte de la obra original, aun cuando esta no sea una parte sustancial, para que pueda configurarse una infracción al derecho de propiedad intelectual salvo que dicha copia tenga la naturaleza de minimis - (Bently y otros, 2018: 208).

21. Sobre el concepto de obra y su importancia en el sistema británico, véase Sherman (2011). Sobre la importancia de la propiedad sobre lo intangible o inmaterial para el desarrollo histórico de la propiedad intelectual, véase Bently y Sherman (1999: 9-60). Para un análisis sobre cómo el derecho de propiedad comodifica lo inmaterial y lo introduce al mercado, véase Drahos (1996: 95-118). 
Sin embargo, el TJUE limitó esta posibilidad al señalar que la parte copiada debe, asimismo, ser original:

La reelaboración de un extracto de una obra protegida por el derecho de autor, concretamente un total de once palabras consecutivas en el asunto principal, será una reproducción parcial en el sentido del artículo 2 de la Directiva 2001/29 si el citado extracto contiene algún elemento capaz de expresar la creación intelectual propia del autor, lo cual corresponde verificar al tribunal remitente (Infopaq, párr. 48; énfasis añadido).

Es importante notar que la interpretación del TJUE en Infopaq supone un análisis distinto a la evaluación que tradicionalmente llevaban a cabo las cortes británicas. Bajo la interpretación tradicional del copyright, las cortes deben reconstruir el objeto inmaterial efectivamente protegido desde la forma tangible en que se materializa el esfuerzo intelectual del autor. Es decir, para determinar si lo copiado es una parte sustancial de la obra original se debe, primero, reconstruir el objeto inmaterial protegido, para luego evaluar si lo tomado por el demandado es sustancial o no. En cambio, bajo el test del TJUE, lo importante es si acaso la parte tomada desde la obra es original o no. Es decir, la relación entre la parte y el todo de la obra es irrelevante: si la parte copiada es original, entonces es protegida, sin importar si dicha parte es o no sustancial para la obra original en su totalidad.

La interpretación del TJUE ha influido directamente en la forma en que las cortes británicas han entendido el análisis de infracciones al copyright post-Infopaq (Alexander, 2009; Hopper, 2011). Así, por ejemplo, en el caso Newspaper Licensing Agency Limited con Marks \& Spencer Plc ([2001] UKHL 38), el Tribunal Superior de Inglaterra y Gales utilizó el criterio del TJUE para determinar si las reproducciones de partes de artículos de periódicos por parte de Marks \& Spencer constituían una infracción al derecho de propiedad intelectual o no. Al respecto, el Tribunal señaló que la cualidad relevante para determinar si una parte de la obra era sustancial o no era «la originalidad de aquello que ha sido copiado» (párr. 19). Es decir, para el Tribunal ya no fue necesario determinar, primero, cuál era el objeto protegido ni, segundo, si lo copiado era sustancial para la obra completa. En cambio, el Tribunal solo se preguntó si la parte copiada era o no original. En este sentido, el Tribunal acogió el criterio interpretativo del TJUE, cambiando la forma de análisis tradicional del copyright: lo importante es la originalidad de la parte copiada, no si lo copiado es una parte sustancial de la obra en su totalidad.

El cambio que la interpretación del TJUE generó en el derecho británico ha generado que los límites físicos del objeto protegido por el copyright ya no sean necesarios para el análisis de infracción de los derechos del autor. En palabras de Jonathan Griffiths (2013: 784), «el derecho parece preocuparse de la protección de la creatividad per se, no en la creatividad dentro de un contexto particular y, luego de Infopaq, 
los límites de la obra protegida parecen tener poca relevancia para el análisis de infracción». Este proceso de desmaterialización del objeto susceptible de protección ha tenido un efecto expansivo, pues, antes de Infopaq, era posible que partes originales de una obra pudieran ser utilizadas por terceros sin necesidad de autorización por parte del autor si es que dichas partes no eran sustanciales con respecto a la obra en su totalidad. Sin embargo, luego de Infopaq, esas partes insustanciales, pero originales, se encuentran protegidas por el copyright, lo que, en definitiva, limita las libertades de los usuarios para crear «sobre» las obras ya existentes. Es decir, mediante la expansión del concepto de infracción, la esfera de libertades de los usuarios se vio considerablemente reducida.

\section{Conclusiones}

De acuerdo a la narrativa tradicional, el derecho de autor nació de la necesidad de retribuir al autor de nuevas creaciones, pues estas suponen un aporte para el desarrollo y bienestar de la sociedad. Desde sus origines, también ha existido la necesidad de mantener un balance entre los derechos otorgados a los creadores y las libertades de los usuarios para interactuar con las obras protegidas. Este balance se ha intentado mantener, tradicionalmente, con el reconocimiento de limitaciones y excepciones al derecho de autor (Burrel y Coleman, 2005; Hudson, 2020), y mediante la idea del dominio público (Boyle, 2003, 2008; Waelde y MacQueen, 2007). Sin embargo, el derecho de autor contemporáneo parece haber perdido dicho balance, inclinándose cada vez más hacia la protección total del titular del derecho de autor. Este desarrollo expansivo del derecho de autor ha puesto en riesgo las posibilidades de interacción que los usuarios pueden llevar a cabo con las obras protegidas.

Dentro de ese contexto, este trabajo ha tenido por objetivo mostrar cómo la jurisprudencia del TJUE ha influido, mediante su actividad interpretativa, en el copyright. Además, ha mostrado cómo el proceso descrito en las secciones anteriores ha llevado a una asimilación entre las tradiciones del derecho de autor continental y del copyright. Este proceso de asimilación ha resultado en la expansión de las categorías tradicionales del copyright británico, en particular, los conceptos de obra, objeto de protección e infracción.

Como se mostró en la tercera sección de este trabajo, el concepto tradicional de originalidad del copyright (Walter con Lane, University of London Press con University Tutorial Press e Interlego AG con Tyco Industries) ha sido, al menos lingüísticamente, asimilado al estándar de originalidad del derecho de autor continental (Temple Island con New English Teas); asimismo, la idea de la lista taxativa de «obras» objeto de protección del copyright ha sido puesta en duda por parte de la jurisprudencia del TJUE post-Infopaq, en lo que podría considerarse como el colapso de los límites entre los conceptos de obra y originalidad; por último, el contenido del concepto infracción en 
el copyright también ha sido influenciado directamente por su contrapartida continental. Todos estos cambios han generado una expansión del copyright en los términos definidos en la primera sección del trabajo. Es decir, los cambios interpretativos generados por Infopaq en el derecho británico tienen, en general, la característica de aumentar el control que los autores tienen sobre sus obras en contraposición a las libertades de los usuarios para interactuar con ellas.

Pareciera ser, además, que la tendencia expansiva de la jurisprudencia del TJUE no cambiará en el futuro cercano. Durante 2019, el TJUE sostuvo interpretaciones expansivas de los derechos reconocidos a los autores en Cofemel con G-Star Raw CV (C683/17), manteniendo la idea base de una alta protección de los derechos reconocidos por la Directiva InfoSoc a los autores (Pelham GmbH y Otros con Ralf Hutter $y$ Otros (C-476/17)). Sin embargo, el proceso de integración entre el derecho de autor europeo y el copyright puede verse detenido, o al menos limitado, en los nuevos casos tras el Brexit, por lo que existen aún pocas certezas respecto al desarrollo que tendrá el copyright. ${ }^{22}$

Como se ha mostrado, el proceso de armonización del derecho europeo ha expandido la esfera de protección de los autores y de quienes ostentan los derechos patrimoniales sobre ellas en el contexto del derecho británico. Como contrapartida, dicha expansión restringe las libertades de los usuarios para acceder a las obras, copiarlas o utilizarlas para nuevas creaciones propias. El proceso de expansión del derecho británico ${ }^{23}$ es solo una muestra del fenómeno general de expansión que ha sufrido el derecho de autor (Chander y Sunder, 2004; Boyle, 2008; Sunder, 2012), el cual, como señalamos al comienzo de este trabajo, no solo tiene consecuencias negativas para el ejercicio de las libertades y derechos fundamentales de los usuarios, sino que también puede llegar a entorpecer la labor del derecho de autor como incentivo para la creación de nuevas obras (Heller, 2013).

Este trabajo ha sido, por tanto, un intento de mostrar una forma sustantiva de entender la expansión del derecho de autor. Esta mirada al fenómeno expansivo supone analizar cómo distintas interpretaciones de los conceptos básicos del sistema modifican el alcance de la protección que el derecho de autor otorga. Queda pendiente,

22. El gobierno británico publicó el 30 de enero de 2020 una guía sobre los cambios que habrá en la regulación luego del 1 de enero de 2021: «Protecting copyright in the UK and EU», Gov.uk, disponible en https://bit.ly/3FPZz3H.

23. El cual no solo ha respondido a la influencia de la jurisprudencia del TJUE, sino que también a la adaptación propia del derecho británico a las particularidades de su sistema jurídico y económico. Véase, por ejemplo, cómo la CDPA, en su sección 9(3), protege las obras literarias, dramáticas, musicales o artísticas, creadas mediante programas computacionales, asumiendo como su autor a la persona que ha elaborado los arreglos necesarios para que dicha creación pueda efectuarse. Esta disposición, que abre las puertas para la protección de obras creadas mediante inteligencia artificial, es un desarrollo propio del derecho británico que no tiene correlato en el derecho europeo. 
sin embargo, dar con soluciones efectivas para limitar la expansión del sistema. De momento, un primer paso es notar cómo opera y qué naturaleza tiene la expansión del derecho de autor.

\section{Referencias}

Alexander, Isabella (2009). «The concept of reproduction and the "temporary and transient" exception». The Cambridge Law Journal, 68 (3): 520-523. DOI: 10.1017/ Sooo8197309990419.

Aplin, Tanya y Jennifer Davis (2017). Intellectual property law: Text, cases and materials. 2. ${ }^{a}$ ed. Oxford: Oxford University Press. DOI: 10.1093/he/9780198743545.001.0001.

BArron, Anne (2002). "Copyright law and the claims of art». Intellectual Property Quarterly, 4: 368-401. DOI: 10.2139/ssrn.346361.

Bently, Lionel (2008). «R. v The Author: From death penalty to community service: 2oth Annual Horace S. Manges Lecture, Tuesday, April 10, 2007». Columbia Journal of Law and the Arts, 32 (1): 1-110.

BentLY, Lionel y Brad Sherman (1999). The making of intellectual property law. Cambridge: Cambridge University Press.

Bently, Lionel, Brad Sherman, Dev Ganjee y Phillip Johnson (2018). Intellectual property law. $5 .^{a}$ ed. Oxford: Oxford University Press.

Biagioli, Mario (2011). «Genius against copyright: Revisiting Fichte's proof of the illegality of reprinting». Notre Dame Law Review, 86 (5): 1.847-1.868. Disponible en https://bit.ly/3FTkDGj.

BIRON, Laura y Elena Cooper (2016). «Authorship, aesthetics and the artworld: Reforming copyright's joint authorship doctrine». Law and Philosophy, 35 (1): 55-85. DOI: $10.1007 /$ s10982-015-9244-y.

Boyle, James (1996). Shamans, software, \& spleens: Law and the construction of the information society. Cambridge, Massachusetts y Londres: Harvard University Press.

-. (2003). «The second enclosure movement and the construction of the public domain». Law and Contemporary Problems, 66 (1-2): 33-74. Disponible en https://bit. ly/3HW 5 mGL.

-. (2008). The public domain: Enclosing the commons of the mind. New Haven y Londres: Yale University Press.

Burrel, Robert y Allison Coleman (2005). Copyright exceptions: The digital impact. Cambridge: Cambridge University Press.

Chander, Anupam y Madhavi Sunder (2004). «The romance of the public domain». California Law Review, 92 (5): 1.331-1.373. DOI: 10.2307/3481419.

Cohen, Julie (2006). «Copyright, commodification, and culture: Locating the public 
domain». En L. Guibault y O. Hugenholtz (editores), The future of the public domain (pp. 121-166). Holanda: Kluwer Law International.

DeAzley, Ronan (2006). Rethinking copyright: History, theory, language. Londres: Edward Elgar.

Derclaye, Estelle (2010). «Infopaq International A/S v Danske Dagblades Forening (C-5/08): Wonderful or worrisome? The impact of the ECJ ruling in Infopaq on UK Copyright Law». European Intellectual Property Review, 32 (5): 247-251.

Drahos, Peter (1996). A philosophy of intellectual property. Londres y Nueva York: Routledge.

GinsBuRG, Jane C. (1990). «A tale of two copyrights: Literary property in revolutionary France and America». Tulane Law Review, 64 (5): 991-1.031. Disponible en https://bit.ly/3DZRJnI.

Goldstein, Paul (2003). Copyright's highway: From Gutenberg to the celestial jukebox. Stanford: Stanford University Press.

Greenleaf, Graham y David Lindsay (2018). Public rights: Copyright's public domain. Cambridge: Cambridge University Press. DOI: 10.1017/9781316460214.

Griffiths, Jonathan (2009). "The "three-step test" in European Copyright Law: Problems and solutions». Intellectual Property Quarterly, 4: 428-457.

-. (2013). «Dematerialization, pragmatism and the European copyright revolution». Oxford Journal of Legal Studies, 33 (4): 767-79o. DOI: 10.1093/ojls/gqto17.

HABERMAS, Jurgen (1986). «Law as medium and law as institution». En Gunther Teubner (editor), Dilemmas of law in the Welfare State. Berlín y Boston: W. de Gruyter.

HaNDIG, Christian (2010). «Infopaq International A/S v Danske Dagblades Forening (C-5/o8): Is the term "work" of the CDPA 1988 in line with the European directives?». European Intellectual Property Review, 32 (2): 53-57. Disponible en https:// www.jstor.org/stable/2456280o.

Heller, Michael (2013). «The tragedy of the anticommons: A concise introduction and lexicon». The Modern Law Review, 76 (1): 6-25. Disponible en https://bit. ly/30ZPcer.

HOPPER, Thomas (2011). «Reproduction in part of online articles in the aftermath of Infopaq (C-5/08): Newspaper Licensing Agency Ltd v Meltwater Holding BV». European Intellectual Property Review, 33: 331-333.

Hudson, Emily (2020). Drafting copyright exceptions: From the law in books to the law in action. Cambridge: Cambridge University Press.

Hugenholtz, Bernt (2013). «Is harmonization a good thing? The case of the copyright acquis». En Justine Pila y Ansgar Ohly (editores), The Europeanization of Intellectual Property Law (pp. 57-74). Oxford: Oxford University Press.

HuLL, Gordon (2019). The biopolitics of intellectual property: Regulating innovation and personhood in the Information Age. Cambridge: Cambridge University Press. 
Leiter, Brian (1999). «Positivism, formalism, realism». Columbia Law Review, 99: 1.138-1.164. Disponible en https://bit.ly/3FKIolm.

Lessig, Lawrence (2004). Free culture: The nature and future of creativity. Nueva York: Penguin Books.

Litman, Jessica (1999). «The public domain». Emory Law Journal, 39 (4): 965-1.023. Disponible en https://bit.ly/3 $\mathrm{HW}_{9} \mathrm{BCb}$.

LIU, Jiabo (2013). Copyright industries and the impact of creative destruction: Copyright expansion and the publishing industry. Londres y Nueva York: Routledge.

Netanel, Neil Weinstock (1996). «Copyright and a democratic civil society». The Yale Law Journal, 106 (2): 283-387. DOI: 10.2307/797212.

PILA, Justine y Paul Torremans (2016). European Intellectual Property Law. 2. ${ }^{a}$ ed. Oxford: Oxford University Press.

Rosati, Eleonora (2019). Copyright and the Court of Justice of the European Union. 1. ${ }^{\mathrm{a}}$ ed. Oxford: Oxford University Press.

Rose, Mark (1988). «The author as proprietor: Donaldson v. Becket and the genealogy of modern authorship». Representations, 23: 51-85. DOI: 10.2307/2928566.

Senftleben, Martin (2010). «The international three-step test: A model provision for EC fair use legislation». JIPITEC: 67-82.

SHERMAN, Brad (2011). «What is a copyright work?». Theoretical Inquiries in Law, 12: 99-121. Disponible en https://bit.ly/3lbVH59.

Sherman, Brad y Leanne Wisemann (2012). «Copyright: When old technologies were new». En Brad Sherman y Leanne Wiseman (editores), Copyright and the challenge of the new (pp-1-10). Amsterdam: Kluwer International.

Sunder, Madhavi (2012). From goods to a good life: Intellectual property and global justice. New Haven y Londres: Yale University Press.

Teubner, Gunther (1987). «Juridification concepts, aspects, limits, solutions». En Gunther Teubner (editor), Juridification of social spheres: A comparative analysis in the areas of labor, corporate, antitrust and social welfare law (pp. 3-48). Berlín y Nueva York: W. de Gruyter.

Unger, Roberto (1986). The critical legal studies movement. Harvard: Harvard University Press.

WAELDE, Charlotte y Hector MacQueen (2007). Intellectual property: The many faces of the public domain. Cheltenham: Edward Elgar.

Walker, Elisa (2014). Manual de propiedad intelectual. Santiago: Thomson Reuters.

Woodmansee, Martha (1984). «The genius and the copyright: Economic and legal conditions of the emergence of the "author"». Eighteenth Century Studies, 17 (4): 425-448. DOI: $10.2307 / 2738129$. 


\section{Sobre el autor}

Felipe Osorio Umaña es abogado. Licenciado en Ciencias Jurídicas y Sociales por la Universidad de Chile. Actualmente realiza sus estudios doctorales en University College London, Faculty of Laws, Reino Unido. Su correo electrónico es felipe.osorio.19@ucl.ac.uk. (1D https://orcid.org/oooo-0002-0727-0324. 


\title{
REVISTA CHILENA DE DERECHO Y TECNOLOGÍA
}

La Revista Chilena de Derecho y Tecnología es una publicación académica semestral del Centro de Estudios en Derecho Informático de la Facultad de Derecho de la Universidad de Chile, que tiene por objeto difundir en la comunidad jurídica los elementos necesarios para analizar y comprender los alcances y efectos que el desarrollo tecnológico y cultural han producido en la sociedad, especialmente su impacto en la ciencia jurídica.

\author{
EDITOR GENERAL \\ Daniel Álvarez Valenzuela \\ (dalvarez@derecho.uchile.cl) \\ SITIO WEB \\ rchdt.uchile.cl \\ CORREO ELECTRÓNICO \\ rchdt@derecho.uchile.cl \\ LICENCIA DE ESTE ARTÍ́CULO \\ Creative Commons Atribución Compartir Igual 4.o Internacional
}

\begin{abstract}
s
La edición de textos, el diseño editorial

y la conversión a formatos electrónicos de este artículo

estuvieron a cargo de Tipográfica

(www.tipografica.io).
\end{abstract}

